\title{
Estudio sobre la identificación de talentos, competencias y habilidades para el desarrollo de la marca personal
}

\section{Study on the identification of talents, competencies and skills for the development of the personal brand}

José Sixto García, Universidad de Santiago de Compostela - jose.sixto@usc.es

\section{Resumen}

Partiendo de la idea de que las marcas personales siguen el mismo proceso de construcción y explotación que las marcas comerciales, la investigación se centra en indagar cómo se potencia el desarrollo del marketing personal en el alumnado desde la Educación Secundaria Obligatoria. Empleando la triangulación metodológica se realiza un análisis de la percepción de los estudiantes acerca de la potenciación del talento y las capacidades individuales. Los resultados desvelan el grado de tratamiento de la marca personal para el posterior desarrollo del marketing personal.

\section{Palabras clave}

Marketing personal; marca personal; talento; competencias; habilidades.

\section{Abstract}

From the idea that personal brands follow the same process of construction and exploitation trademarks, the study focuses on investigating how the system powers marketing development in students from secondary education. According to a methodological triangulation method, we analyze the perception of students about their empowerment of talent and individual capacities. The results reveal the degree of processing of personal branding for the further development of personal marketing.

Keywords

Personal marketing; personal brand; talent; skills; abilities.

Sumario

1. Introducción: la construcción de la marca personal. 1.1 Misión y visión en la senda del talento. 2. Objetivos de la investigación y metodología. 3. Resultados de la investigación. 4. Conclusiones finales. 5. Bibliografía 


\section{Introducción: la construcción de la marca personal}

Las marcas personales siguen el mismo proceso de construcción que las marcas comerciales. En primer lugar, debemos decidir acerca de los niveles sobre los que se creará la identidad de marca, puesto que las marcas varían en función del poder y del valor que tienen en el mercado. Hay marcas que todos conocemos, otras que nos suenan pero que poseen un nivel de identificación menor, y otras que gozan de preferencia de marca porque los usuarios las seleccionan frente a las competidoras y gozan de un alto nivel de fidelidad entre sus consumidores. Obviamente una marca será más poderosa -tendrá mayor valor de marca (Aaker, 1991)- si cuenta con lealtad por parte de los usuarios, conocimiento de marca, calidad percibida, fuertes asociaciones y otros activos como patentes, marcas registradas y relaciones con el canal de distribución.

$\mathrm{Ni}$ todas las marcas nos sugieren lo mismo ni todas las marcas presentan la misma etiqueta de calidad. Ni las personales ni las comerciales. A una marca bien construida y bien consolidada se le exigen cuatro estándares que denotan su calidad (Kotler et al., 2002):

a) Atributos. La marca debe sugerir algo acerca de las particulares del producto.

b) Beneficios. Sin embargo, los usuarios no buscan atributos, sino beneficios, de manera que los atributos se deben transformar en beneficios funcionales y emocionales.

c) Valor. La marca debe sugerir acerca de su valor para el usuario.

d) Personalidad. Toda buena marca ha de proyectar personalidad para atraer a las personas que posean o deseen poseer una imagen semejante a la que proyecta la marca.

El experto en marketing, Tom Peters, fue el primero en hacer alusión al concepto de personal branding o marca personal en su artículo "The Brand Called You" publicado en 1997 en la revista Fast Company. En el texto dice que todos somos jefes de nuestra propia empresa cuyo nombre es "Yo S. L.". Peters nos plantea la siguiente pregunta: “¿Cuándo fue la última vez que te preguntaste qué querías ser en la vida? Pues pregúntatelo otra vez. Ahora". En palabras de Arqués (2007) la aportación de Peters viene a significar que la probidad a la empresa pierde puntos y que ahora lo que realmente cuenta es que los colaboradores aporten valor. En efecto, cada vez más, definir y demostrar cuáles son nuestros valores personales no es un capricho, sino una opción de supervivencia laboral.

La cultura del Personal Brand Development surgió en Estados Unidos y poco a poco se fue expandiendo e instaurando en otros mercados. Philip Kotler, junto a Rein, Hamlin y Stoller, fueron los primeros en teorizar la llamada industria de la visibilidad en la obra High Visibility. Transforming Your Personal and Professional Brand. Otro de los grandes especialistas en Dirección y Administración de Empresas, Peter Drucker, expone una visión más historicista para explicar el concepto de marca personal. Se remonta a los orígenes del protestantismo para justificar la importancia de conocer y comunicar con ventaja las fortalezas y las oportunidades de la marca persona. Las reflexiones de Peters fueron ampliadas por Drucker en 1999 en el artículo "Managing Onesefl" en el que reconocía la fuerza del individuo en el nuevo entorno. Drucker (2005) argumenta que gestionarse a uno mismo exige que cada trabajador del Conocimiento piense y se comporte como un consejero delegado. Y añade que en la Economía del Conocimiento solo tienen éxito quienes se conocen a sí mismos: sus puntos fuertes, sus valores y cómo logran sus mejores resultados.

El auténtico valor de las marcas personales lo aportan sus habilidades. Si en el terreno personal estas habilidades determinan la manera cómo nos perciben los demás al relacionarnos en el entorno familiar o con los amigos, en el terreno profesional influyen en la capacidad para relacionarnos con los compañeros de trabajo, con los proveedores u otras empresas, en nuestra especialización para realizar determinado tipo de tareas, en ese sexto sentido de la intuición para vislumbrar lo que otros no son capaces de percibir, en la resolución de conflictos en tiempo y forma, en la creatividad, en las dotes artísticas, en el don de gentes, en la buena presencia, en el estilo, en la elegancia, en el desarrollo de la comunicación no verbal, en el dominio de idiomas, en la puntualidad y en el cumplimiento de horarios, en las buenas maneras, en la educación, en saber escuchar y en saber ordenar, en liderar equipos y en dejar que otros nos lideren, etc.

Martín (2012) ofrece once razones por las que considera que es necesario comenzar a crear una marca personal propia: (1) porque cualquier trabajo es temporal; (2) porque tu marca es demasiado importante para dejarla al azar; (3) porque todo el mundo merece desarrollar su marca; (4) porque en un mundo de 7.000 millones de personas diferenciarse no es una opción; (5) porque has de tener el control de tu carrera profesional; (6) porque el $80 \%$ de los empleos no se anuncian, se comunican de "boca a oreja"; (7) porque en cualquier portal de búsqueda de empleo hay millones de CV esperando a ser los elegidos; (8) porque si no dices quién eres, los demás lo harán por ti y puede que no te beneficie; (9) porque el personal branding o marca personal forma ya parte de nuestra cultura; (10) porque constantemente tenemos que convencer a empresarios, amigos, familia, profesores... para que actúen y pasen cosas en nuestra vida; y (11) porque nuestros perfiles no descansan, están en la red 24 horas al día en todo el mundo. Estamos siendo observados de manera constante, hasta cuando dormimos.

Las personas no somos un ente estático incapaz de comunicar, sino todo lo contrario: una fuente constante de información que debe autoevaluarse para conseguir así una gestión adecuada que permita transmitir a los demás quiénes somos y lo que somos capaces de hacer. En realidad, cuando tratamos nuestra marca personal estamos haciendo lo mismo que hace un departamento de Marketing al gestionar una marca comercial. En consecuencia, siguiendo a Arruda (2002), algunas de las ventajas de identificar y proyectar nuestra marca personal serían las siguientes:

a) Nos ayuda a entendernos mejor a nosotros mismos.

b) Mejora nuestra autoconfianza.

c) Aumenta nuestra visibilidad.

d) Nos diferencia.

e) Mejora nuestra retribución.

f) Nos ayuda a sobrevivir en tiempos de crisis económica.

g) Nos permite adentrarnos en nuevas áreas de negocio.

h) Nos permite acceder a trabajos menores y más interesantes. 
Por su parte, Catherine Kaputa (2005) señala las diferencias de percepción entre la mentalidad de un trabajador tradicional y la mentalidad del colaborador que trabaja su marca personal, tal y como recogemos en la siguiente tabla:

Tabla 1. Diferencias entre trabajar o no la marca personal

\begin{tabular}{|l|l|}
\hline \multicolumn{1}{|c|}{ Sin marca personal } & \multicolumn{1}{c|}{ Con marca personal } \\
\hline Seguridad laboral & Libertad profesional \\
Trabajo para un jefe & Trabajo para mí \\
Confío en la empresa & Confío en mí \\
\hline Escribo mi curriculum vitae & Desarrollo mi plan de marketing \\
\hline Pienso a corto plazo & Pienso a largo plazo \\
Busco un trabajo & Salgo al mercado \\
Trabajo & Soluciono los problemas de mis clientes \\
\hline Habilidades y competencias & Añado valores y recursos \\
\hline Mi objetivo es encajar & Mi objetivo es diferenciarme \\
\hline Me baso en la perseverancia & Me baso en la estrategia \\
\hline Realizo transacciones & Construyo relaciones duraderas en el tiempo y \\
& busco consolidarlas \\
\hline
\end{tabular}

Fuente: elaboración propia a partir de Kaputa (2005)

Cuando alguien explota su marca personal también se producen cambios de matiz con respecto a las relaciones que mantiene con la empresa y al papel que representa dentro de ella:

Delegar, dar poder, empowerment: son los individuos los que otorgan su poder a la empresa y no al revés.

- Recursos humanos: las personas han dejado de ser un recurso o, mejor dicho, de ser tratadas como un recurso por parte de las empresas. Las personas son fuentes de talento que aportan valor a la empresa.

- Trabajar para uno mismo. La gente no trabaja para el jefe ni porque el jefe le ordena. La gente trabaja para sí misma porque forma parte de su proyecto, porque se ha marcado unos objetivos o porque necesita el dinero.

Así pues, podemos decir que la marca personal es la manera de clarificar y comunicar aquello que nos hace diferentes y especiales, y de emplear esas cualidades para guiar nuestra carrera o tomar nuestras decisiones estratégicas. Se trata de comprender cuáles son los atributos -fortalezas, debilidades, valores y pasiones- que nos hacen únicos y de emplearlos para diferenciarnos de nuestros competidores y de nuestros iguales. La marca personal consiste, por tanto, en comunicar de modo claro la promesa de valor única que ofrecemos a nuestra empresa 0 a nuestros clientes (Arruda, 2002).

La marca persona permite trazar el camino de nuestro desarrollo profesional ganando contactos estratégicos, potenciando una imagen que refleje nuestros valores y nuestro estilo, estableciendo nuestra credibilidad, generando entusiasmo en torno a nosotros y a nuestros proyectos y consiguiendo las metas laborales y profesionales que nos hayamos marcado. Para lograrlo es imprescindible dibujar un plan individualizado que tenga en cuenta la situación específica de cada persona (Soyunamarca, 2014), ya que ni todos podemos ser la misma marca ni la misma marca valdría para dos.

Pero no nos confundamos al pensar que una marca personal se crea en cinco minutos. La gestión adecuada de una marca será lo que nos permita diferenciarnos en el mercado y ser conocidos (y reconocidos y valorados) por las competencias que nos distinguen como profesionales. Para que la marca personal esté bien definida, sea estable y pueda transmitirse así a nuestros interlocutores debe haber sido forjada, estudiada y evaluada atendiendo a nuestros propios valores internos (qué somos, qué sabemos hacer, cuáles son nuestras competencias y actitudes) y externos (qué nos diferencia del resto). En realidad, crear una marca personal sigue los mismos pasos que la creación de una marca comercial (Arqués, 2007):

1. Definir qué entendemos por nuestra marca personal para poder establecer los valores que nos singularizan.

2. Fijar los objetivos que deseamos lograr a través de nuestra marca.

3. Establecer cuál es nuestro público objetivo.

4. Posicionarnos en el mercado, esto es, saber cuál es nuestra reputación actual y planificar las acciones para adecuarla a nuestros valores y objetivos.

5. Comunicar: transmitir nuestra propuesta a nuestro público objetivo.

6. Revisar, puesto que tanto las situaciones como nosotros mismos cambiamos, por lo que es necesario reajustar nuestra comunicación personal a las exigencias y necesidades del entorno.

\subsection{Misión y visión en la senda del talento}

En una economía que está estandarizando los procesos, homogenizando los productos y convirtiendo a los trabajadores en profesionales de marca blanca es necesario diferenciarse y apostar por el valor añadido que aportamos al mercado. Para conseguirlo la mejor manera es descubrir y comunicar aquello que nos diferencia y nos hace ser percibidos como sobresalientes (Pérez, 2013). Si decíamos antes que la creación de una marca personal es semejante a la de una marca comercial, también es porque las personas tenemos atributos, poseemos valores y ocupamos un lugar (un posicionamiento) en nuestro entorno. 
Dice Pérez Ortega (2008) que podemos definir la marca personal como la percepción que tiene nuestro entorno de los atributos que nos hacen despuntar, diferenciarnos y ser tenidos en cuenta por quienes necesitan nuestros servicios. Pérez va más allá y concreta que descubrir nuestra marca personal es la mejor manera de sobrevivir en un entorno como el actual. Es decir, al definir la marca personal cada persona asume la responsabilidad de convertirse en protagonista de su propio futuro, ya que el personal branding trata sobre el control del proceso que afecta a la forma en que los demás nos perciben y de gestionar esos procesos estratégicamente para ayudarnos a conseguir los objetivos. En consecuencia, se trata de un método para identificar el valor como ser humano, para conseguir que sea ampliamente conocido y con el fin de alimentar y aumentar ese valor a lo largo de la vida.

La confianza es uno de los elementos primordiales que sustenten la marca personal. No se trata de buscar la persona que puedes llegar a ser, sino de descubrir la persona que eres. Todos tenemos nuestros puntos fuertes, solo es cuestión de identificarlos para poder comunicarlos con eficacia. Todas las empresas disponen de una declaración explícita y compartida tanto interna como externamente de su misión, visión y valores que orientan sus actuaciones en el mercado y hacia la sociedad en general. La misión define cuál es nuestra labor o actividad en el mercado con sus singularidades y establece los objetivos que nos marcamos. Espinosa (2012) propone algunas preguntas que pueden ayudarnos a identificar nuestra misión: "¿qué hacemos?, ¿cuál es nuestro negocio?, ¿a qué nos dedicamos?, ¿cuál es nuestra razón de ser?, ¿quiénes son nuestros públicos objetivo?, ¿cuál es nuestro ámbito geográfico de acción?, ¿cuál es nuestra ventaja competitiva?, ¿qué nos diferencia de nuestros competidores? En cambio, la visión establece las metas que pretendemos conseguir en el futuro. Estas metas tienen que ser realistas y alcanzables, ya que la propuesta de visión ha de tener un carácter inspirador y motivador. Para la definición de la visión nos ayudará responder a las siguientes preguntas: ¿qué quiero lograr?, ¿dónde quiero estar en el futuro?, ¿para quién lo haré?, ¿ampliaré mi zona de actuación?

La visión siempre es anterior a la misión; digamos que es una declaración de intenciones más global y a largo plazo que todavía está pendiente de concretar. Sin embargo, la misión es mucho más concreta que la visión y se proyecta a más corto plazo porque es la razón de ser una organización y se materializa en qué se centran sus actividades y los valores que dirigen la actuación de toda la compañía.

Está claro que el objetivo de una marca en el corto, mediano o largo plazo es ocupar un lugar en la mente de los usuarios. El objetivo del personal branding es el mismo, pero aplicado a personas, ya sea de forma individual o como colectivo. Primero se pretende ser recordado, luego ser considerado hasta convertirse en la opción preferida y, así, en la alternativa elegida.

Todas las marcas personales poseen sus propios atributos, de tal modo que los atributos hacen referencia a nuestros conocimientos, habilidades, y actitudes personales y profesionales. Los atributos nos diferencian de los demás, nos hacen únicos y exclusivos, suponen nuestra aportación particular de valor y nos singularizan frente al conjunto de perfiles equiparables al nuestro. No debemos olvidar que la contribución del marketing a la gestión empresarial cambió el significado clásico del término producto y sustituyó aquella visión antigua propia del fabricante, referida a que el producto era simplemente un conjunto de elementos físicos y químicos enlazados de manera que ofrecía unas posibilidades al consumidor. La definición actual considera el producto como un conjunto mucho más amplio y tiene en cuenta la existencia de una función general del producto (Chias, 2008). Por tanto, el concepto de producto, desde la óptica actual del marketing, no debe centrarse en sus características 0 atributos intrínsecos, sino en los beneficios que reporta, las emociones que produce o las experiencias que proporciona (Sixto, 2013).

Al fin y al cabo, cuando presentamos nuestra candidatura a una oferta de trabajo o simplemente por formar parte del mercado laboral, las personas somos un producto. Digamos que quien nos vaya a contratar o quien consuma los servicios que ofrecemos son los usuarios de nuestro productopersona. Como productos nos reciclamos movidos por las exigencias y necesidades del mercado actual, nos diferenciamos de los demás por lo que sabemos hacer y, en definitiva, vamos consolidando nuestra propia marca personal.

Los atributos están vinculados a las competencias que puede ejecutar una persona en el desarrollo de una actividad. El concepto de competencia fue planteado inicialmente por David McClelland en 1973 como una reacción ante la insatisfacción con las medidas tradicionales utilizadas para predecir el rendimiento en el trabajo. Por competencias entendemos el conjunto de conocimientos, habilidades, disposiciones y conductas que posee una persona y que le permiten la realización exitosa de una actividad. Digamos que son las actuaciones integrales que pone en práctica una persona para identificar, interpretar y resolver situaciones con ética, adecuación e idoneidad dentro de un contexto.

Si nos ceñimos al terreno del marketing personal podemos definir la competencia como la capacidad para responder con éxito a una demanda que nos ha sido encargada, atendiendo a los parámetros de nuestra empresa o sector empresarial. Para conseguirlo son necesarios tres elementos: los conocimientos (saber), las actitudes (saber ser) y las habilidades (saber hacer). Spencer y Spencer (1993) consideran que las competencias son una característica subyacente de un individuo, que está causalmente relacionada con un rendimiento efectivo o superior en una situación o trabajo, definido en términos de un criterio. Así las cosas, en la definición de la marca personal encontramos tres tipos de competencias que la persona combina para establecer su propio plan de marketing y también el desarrollo de su ejercicio profesional:

1. Competencias básicas. Son las que se desarrollan en la educación inicial que recibe una persona. Comprenden aquellos conocimientos y habilidades que permiten avanzar en el ciclo educativo e integrarse en la sociedad, como por ejemplo, las áreas de lenguaje y comunicación, las aplicaciones numéricas, la solución de problemas o el manejo de las tecnologías digitales.

2. Competencias conductuales. Se trata de las habilidades y conductas que explican desempeños superiores o destacados en el mundo del trabajo. Lo habitual es que se identifiquen con los atributos que caracterizan a la persona, de modo que por competencia conductual entenderíamos la rigurosidad, la flexibilidad, la orientación al logro o el emprendimiento.

3. Competencias funcionales. Son las competencias técnicas que se exigen para el desempeño de una función laboral según los estándares establecidos por la compañía o por el sector productivo en el que se practican. 


\section{Objetivos de la investigación y metodología}

A partir de la revisión bibliográfica y la consecuente definición de la marca personal y de la identificación de los atributos inherentes a su explotación, la investigación analiza cómo se potencian el talento y las capacidades individuales en la educación secundaria (etapa tras la que se debe elegir entre la formación profesional o el bachillerato) de cara a la detección y el posterior desarrollo del marketing personal.

Como marco para la investigación se ha escogido un Instituto Plurilingüe público ubicado en un contexto urbano (en Santiago de Compostela, España) y que en el curso académico 2014-2015 contaba con un total de 1.179 alumnas y alumnos. El nivel económico de las familias es medioalto y alto; casi todas residen en pisos próximos al centro y las unidades familiares tienen de media cuatro miembros: los padres y dos hijos. Los padres y las madres poseen formación académica superior y muchos son funcionarios y funcionarias, aunque la mayoría trabaja en el sector terciario y otra gran parte regenta algún tipo de negocio o dirige alguna empresa. El nivel económico de las familias, sumado a un entorno urbano y de bienestar donde reside casi la totalidad del alumnado, favorece el acceso a una enseñanza de calidad en lo que a recursos se refiere: dispositivos informáticos, libros de consulta, posibilidades de viajar y conocer mundo, bibliotecas, museos de la ciudad, red de carreteras, etc.

La metodología empleada en esta investigación responde a la llamada triangulación metodológica, ya que combina técnicas cualitativas y cuantitativas para la observación de un mismo fenómeno. Por tanto, nos fundamentamos en una triangulación entre métodos o betweenmethod/across-method que armoniza la utilización de dos o más métodos de investigación diferentes. En este sentido, las técnicas de investigación utilizadas son las siguientes:

a) Técnicas de carácter cualitativo:

1. Observación directa del fenómeno mediante estancia en el Instituto durante dos meses.

2. Entrevista en profundidad a la jefa del departamento de Orientación. En la entrevista se trabajó con escucha empática y fomento del rapport para garantizar la calidad investigadora del diálogo.

b) Técnica de carácter cuantitativo:

1. Cuestionario de respuestas cerradas y respuestas abiertas de respuesta simple enfocado a la evaluación de los niveles de desarrollo del talento y de las capacidades individuales en el centro. El cuestionario lo componían catorce preguntas y fue distribuido en todos los cursos de la Enseñanza Secundaria Obligatoria (ESO). Concebido bajo un modelo tipo test, se orientó para la selección de una única respuesta de entre las posibles soluciones planteadas y, dependiendo de la opción escogida, en algunas preguntas abría camino a otra cuestión de respuesta abierta.

En cuanto a los ítems de estudio, se seleccionaron los siguientes:

a) Identificación del tratamiento en el aula por parte del profesorado y localización de posibles metodologías docentes personalizadas.

b) Valoración de la asistencia obligatoria al instituto y nivel de interés mostrado hacia los estudios.

c) Evaluación de la percepción del grado de preocupación mostrado por el profesorado en el aprendizaje del alumnado.

d) Interpretación de la potenciación del talento, las potencialidades individuales y las capacidades artísticas, y la creatividad.

Se realizaron 25 encuestas en cada curso de la ESO sin hacer discriminaciones de género, es decir, la variable de sexo no se tuvo en consideración, sino que el reparto se hizo sin distinguir entre el número de alumnas y alumnos de cada grupo. La muestra corresponde, pues, a un total de 100 encuestas ( 25 por grupo $x 4$ cursos de ESO). Las variables de localización geográfica, poder adquisitivo y nivel de estudios o formación son las descriptas arriba. Los datos se procesaron mediante el programa Calc, que permite, además, realizar los cruces pertinentes entre las distintas variables.

La utilización de la triangulación se justifica, pues, en la medida en que su uso pretende reforzar la validez de los resultados, así que se usa para asegurar que se realiza una aproximación más comprensiva a la solución del problema de investigación. En esencia, la triangulación implica la validación mutua de los métodos cuantitativos y cualitativos para estudiar un único fenómeno y de los diversos resultados que se desprenden de la utilización de cada uno de esos métodos referidos y, desde esta perspectiva, genera un conocimiento completo del fenómeno social estudiado porque los resultados obtenidos se complementan, lo que permite proporcionar explicaciones sólidas. No se trata, pues, de establecer una precedencia científica de las técnicas cualitativas con respecto a las cuantitativas ni viceversa, pues no solo no se excluyen mutuamente, sino que se refuerzan (Beltrán, 1985) y complementan (Hernández, Fernández y Baptista, 2007).

\section{Resultados de la investigación}

En primer lugar, llama la atención que ocho de cada diez estudiantes de secundaria confiesan que ir a clase les supone una obligación (80\%). Para un $8 \%$ implica, incluso, una pérdida de tiempo y tan solo otro $8 \%$ considera una satisfacción ir al instituto. 
Gráfico 1. Valoración de la asistencia a clase

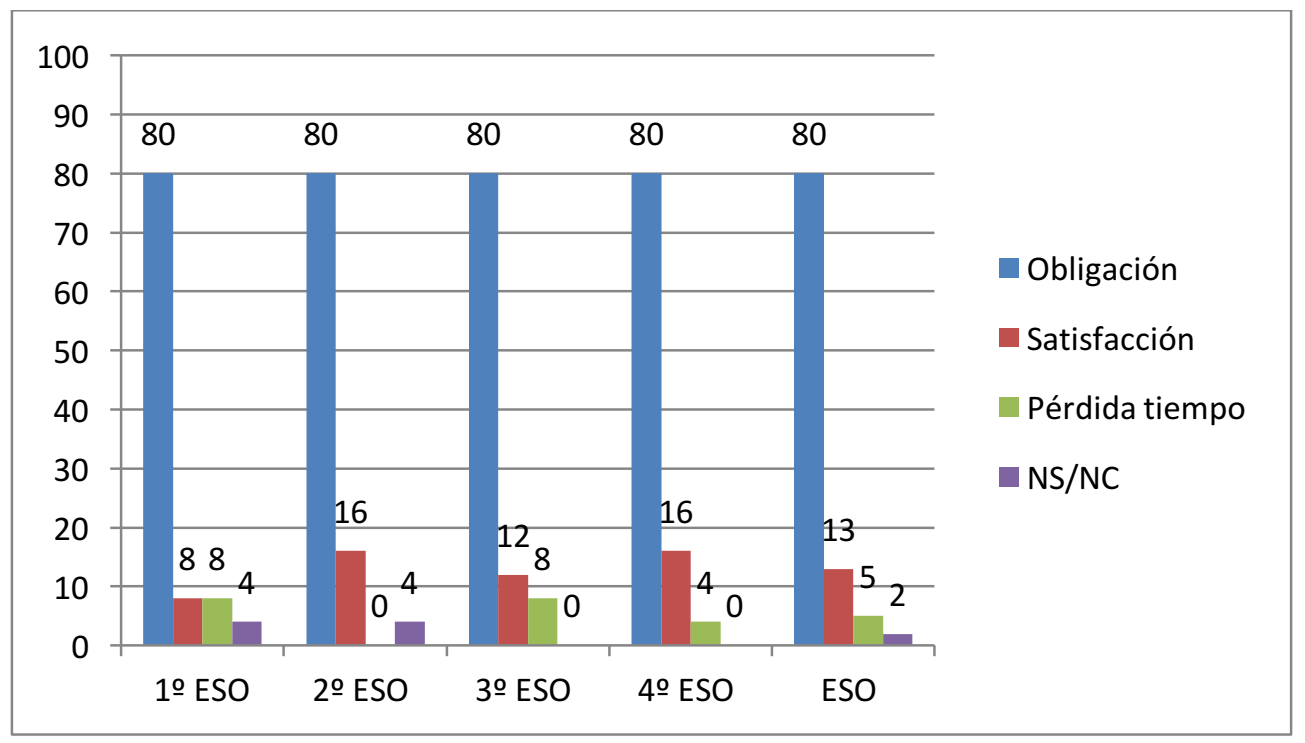

Fuente: elaboración propia.

Tres de cada cuatro estudiantes revelan que se aburren en clase (76\%), aunque solo en algunas asignaturas. A ellos hay que sumar otro $1 \%$ que manifiesta que se aburre en todas las materias porque no le interesa ninguna, de modo que, en total, un $77 \%$ del alumnado se aburre en clase. Por otra parte, los datos demuestran que el porcentaje de estudiantes que se aburren en las aulas incrementa curso a curso:

Gráfico 2. Porcentajes de aburrimiento en clase

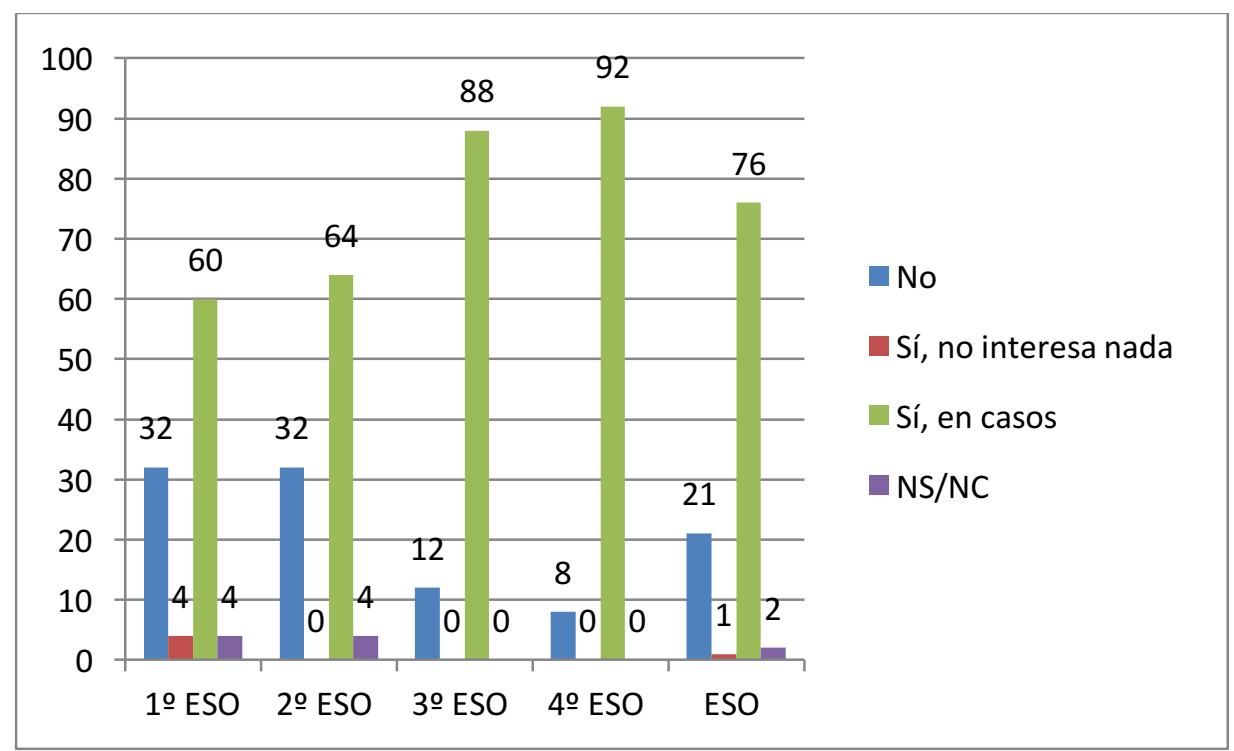

Fuente: elaboración propia.

Aunque no se aprecian diferencias significativas por curso, atendiendo a las materias, las Ciencias Sociales resultan ser la asignatura en la que más se aburre el alumnado de ESO, un $16 \%$ del total, seguidas por Lengua Castellana y Literatura (10\%) y Tecnología (9\%). No podemos deducir, no obstante, que haya una correlación de las materias que provocan mayor desinterés en los diferentes cursos de ESO con el resultado final global, sino que la materia varía en función del curso, por lo que todo parece apuntar a que detrás de la desmotivación se encuentra el papel que juega el docente y no tanto los contenidos curriculares. 
Gráfico 3. Materias que resultan más aburridas para el alumnado

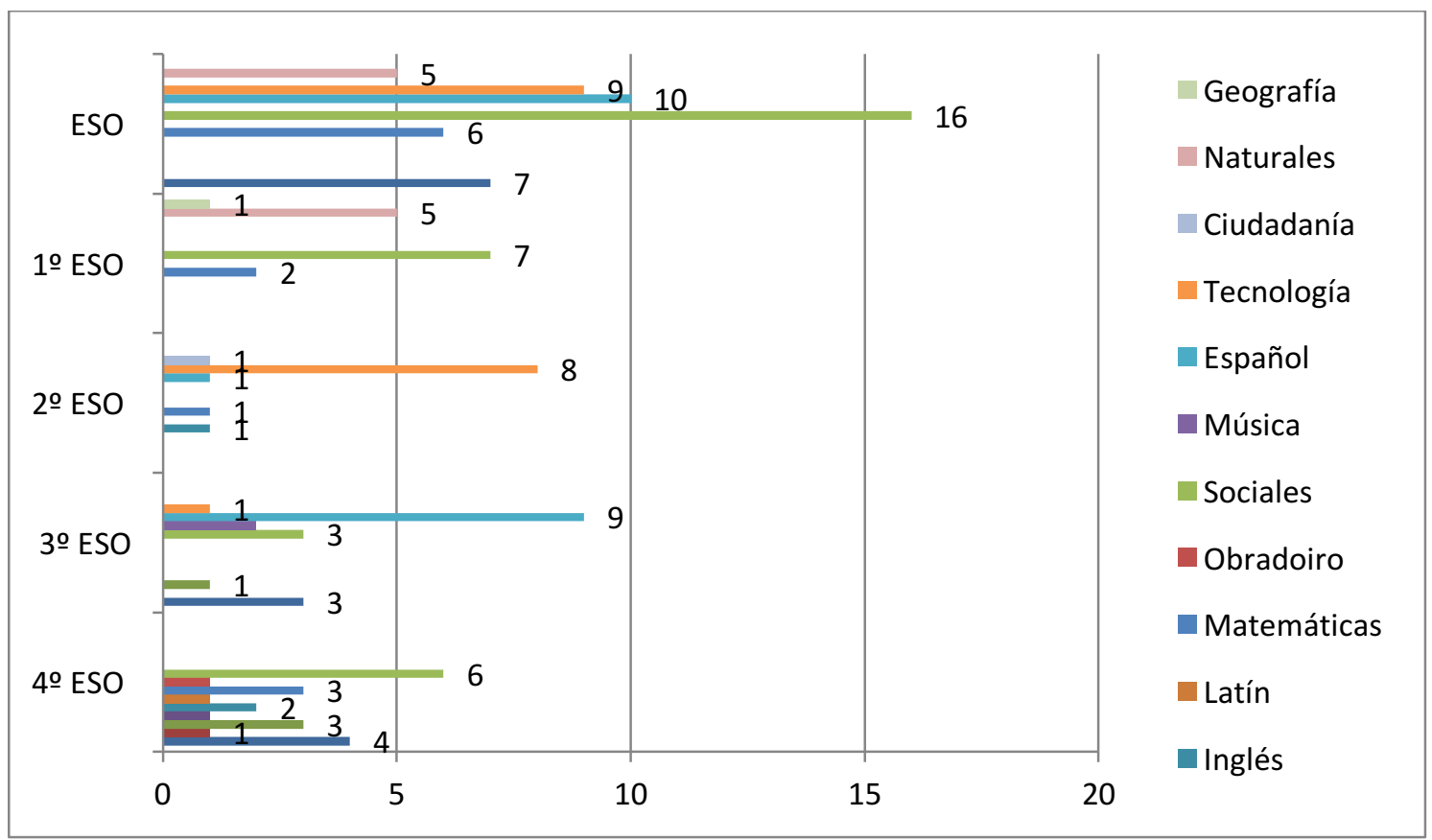

Fuente: elaboración propia.

Al cruzar los datos de los escolares que consideran ir al instituto una obligación con los que se aburren en clase, obtenemos que más de la mitad de estos alumnos y alumnas se aburren durante la jornada escolar (65\%):

Gráfico 4. Porcentaje de alumnado que considera el instituto una obligación y se aburre en clase

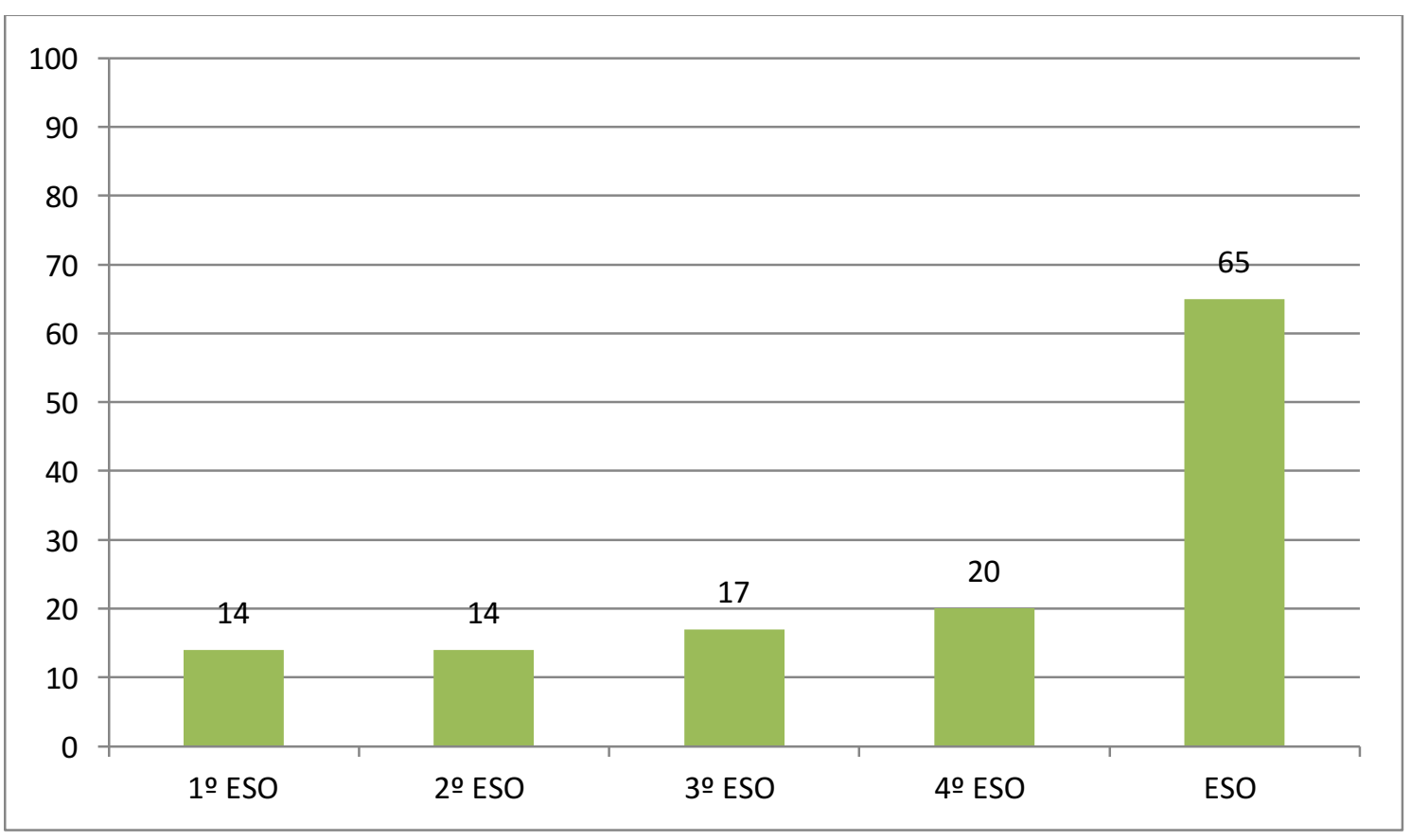

Fuente: elaboración propia. 
Con respecto a la implicación de la figura del docente en la preocupación por el aprendizaje del alumnado no se encuentra una tendencia clara. Un tercio de los estudiantes considera que todo el profesorado se preocupa por su aprendizaje (30\%), mientras que un $38 \%$ entiende que lo hace más de la mitad de los profesores y profesoras y otro $29 \%$ que menos de la mitad del profesorado.

De todas formas, lo que se constata es que solo un $1 \%$ considera que ninguno de sus profesores se preocupa por el aprendizaje de sus alumnos, lo que, en otras palabras, viene a significar que el $99 \%$ del alumnado aprecia preocupación del profesorado por su aprendizaje, aunque esa preocupación varía según los casos:

Gráfico 5. Valoración de la preocupación del profesorado por el aprendizaje del alumnado

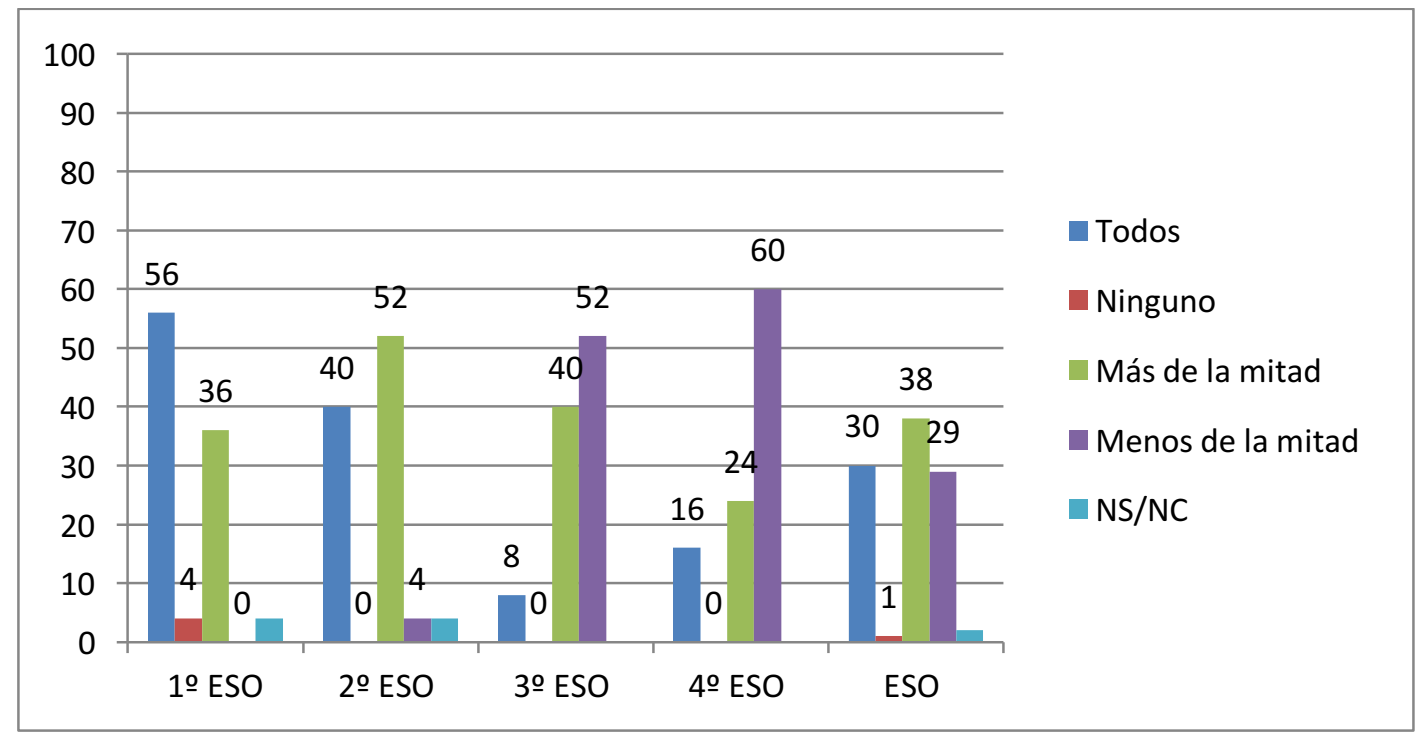

Fuente: elaboración propia.

La mayoría del alumnado (55\%) considera, de igual modo, que el profesorado lo trata como al resto de sus compañeros y compañeras, mientras que un $41 \%$ valora el ejercicio docente como personalizado:

Gráfico 6. Valoración del tratamiento del profesorado al alumnado en la práctica docente

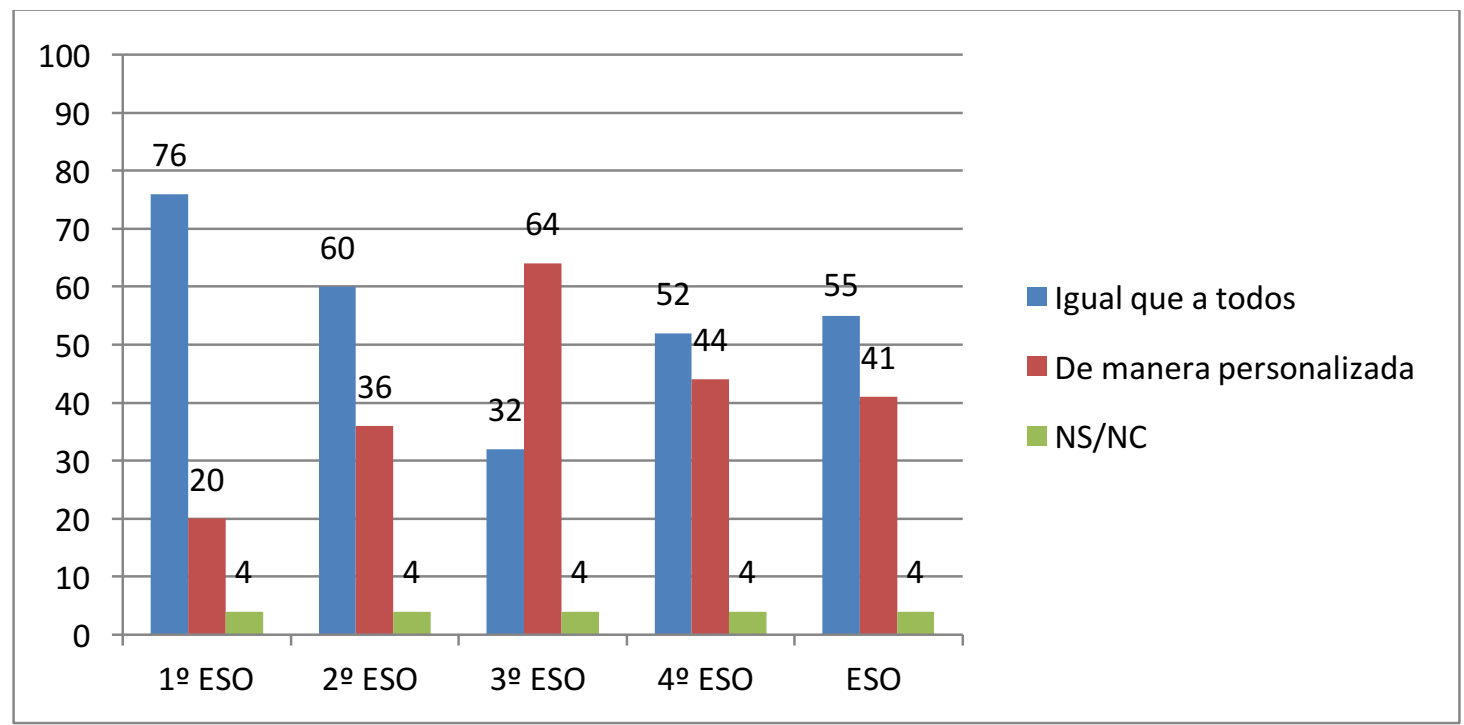

Fuente: elaboración propia. 
Este tratamiento no individualizado no parece repercutir de manera notoria en la interpretación que las alumnas y los alumnos realizan de la potenciación de sus capacidades personales, puesto que la tendencia generalizada es que el $60 \%$ estima que se fomentan sus capacidades individuales, pero solo en algunas materias. A ellos se sumarían los que consideran que en todas las asignaturas se potencian sus capacidades (25\%), por lo que solo uno de cada diez estudiantes (10\%) siente que sus capacidades no se explotan en ninguna disciplina:

Gráfico 7. Potenciación de las capacidades individuales

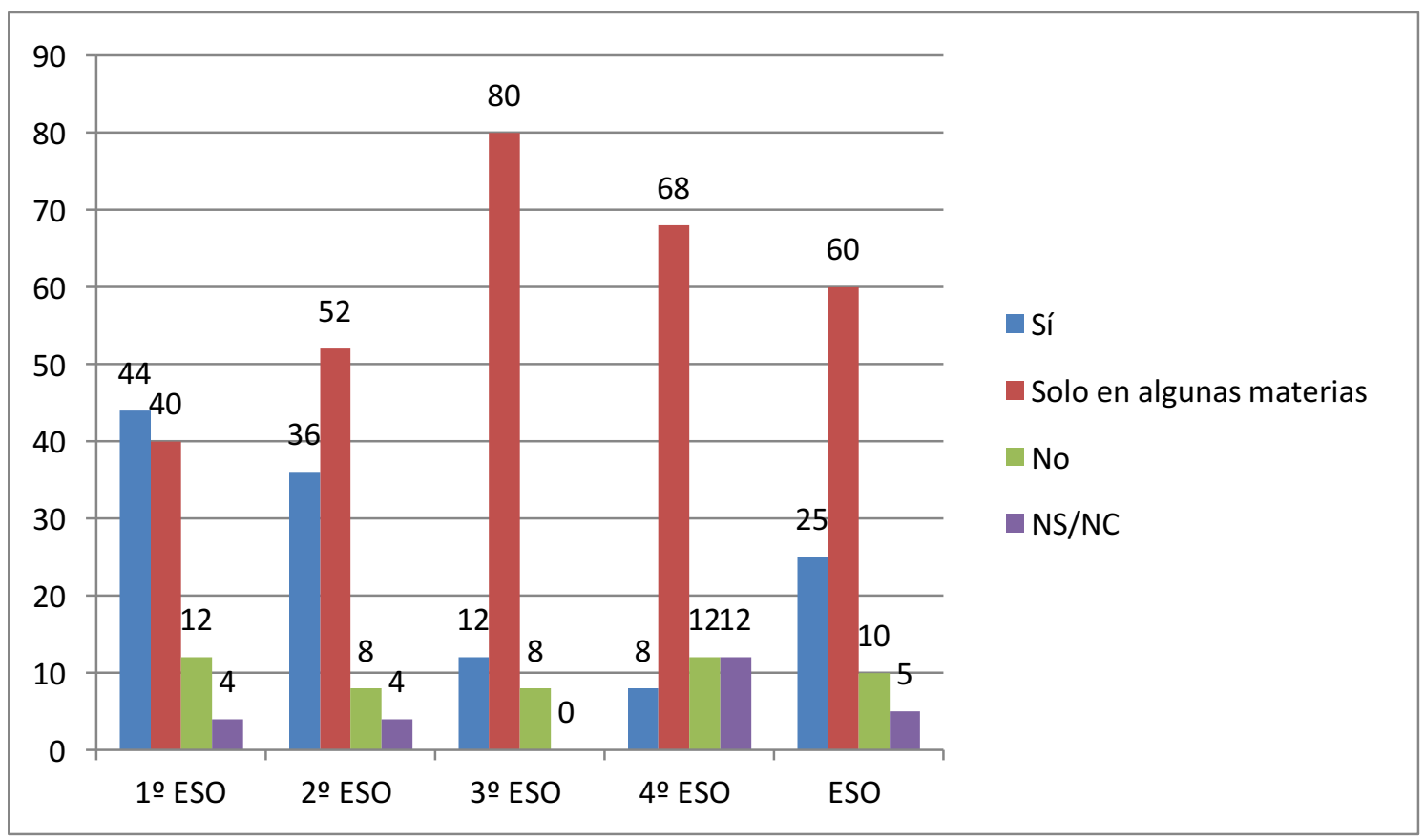

Fuente: elaboración propia.

De los que no se aburren en clase, el $20 \%$ considera que se potencian sus capacidades individuales y otro $20 \%$ que se hace lo mismo con el desarrollo de sus talentos personales.

Sin embargo, a pesar de estos resultados, sorprende que la práctica totalidad del alumnado (88\%) considera que hay unas materias más importantes que otras:

Gráfico 8. Importancia concedida a las diferentes materias

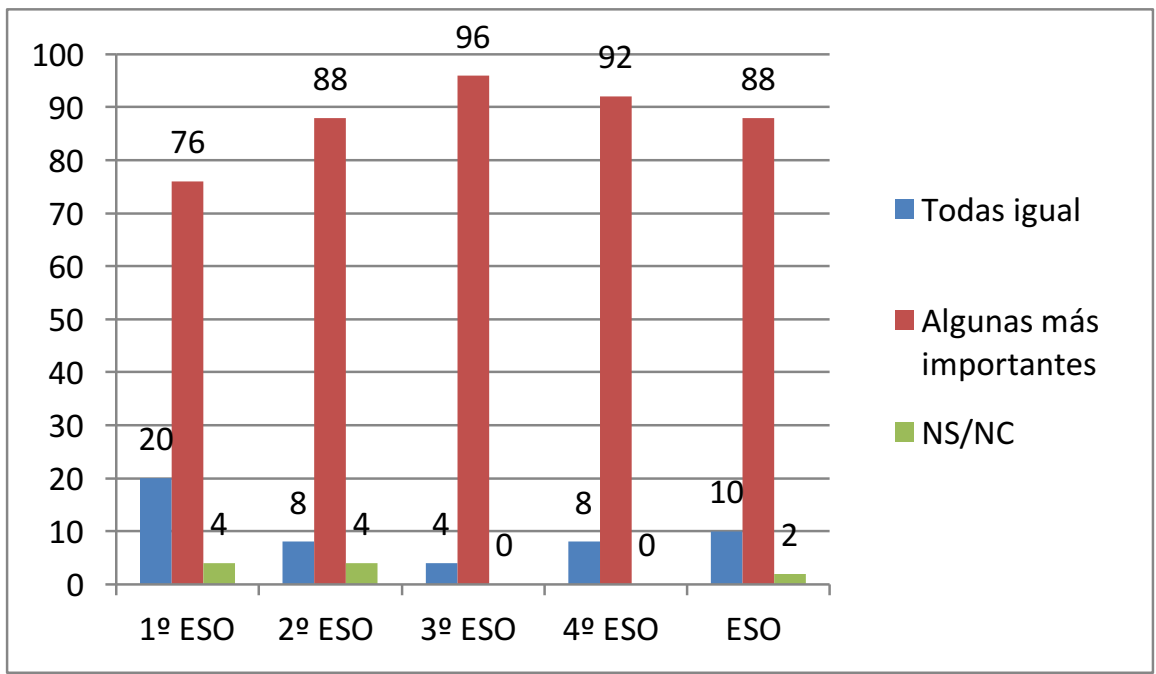

Fuente: elaboración propia. 
En efecto, de ese $88 \%$ que entiende que las distintas áreas de conocimiento tienen diferente importancia en la vida académica personal, la mayoría (59\%) considera que Matemáticas es la materia más importante de la ESO, seguida de lejos por Lengua Castellana y Literatura (18\%), mientras que Música es considerada la asignatura menos importante para un cuarto de esos estudiantes (24\%):

Gráfico 9. Comparativa entre las materias consideradas más y menos importantes por el alumnado

\section{Más importantes}

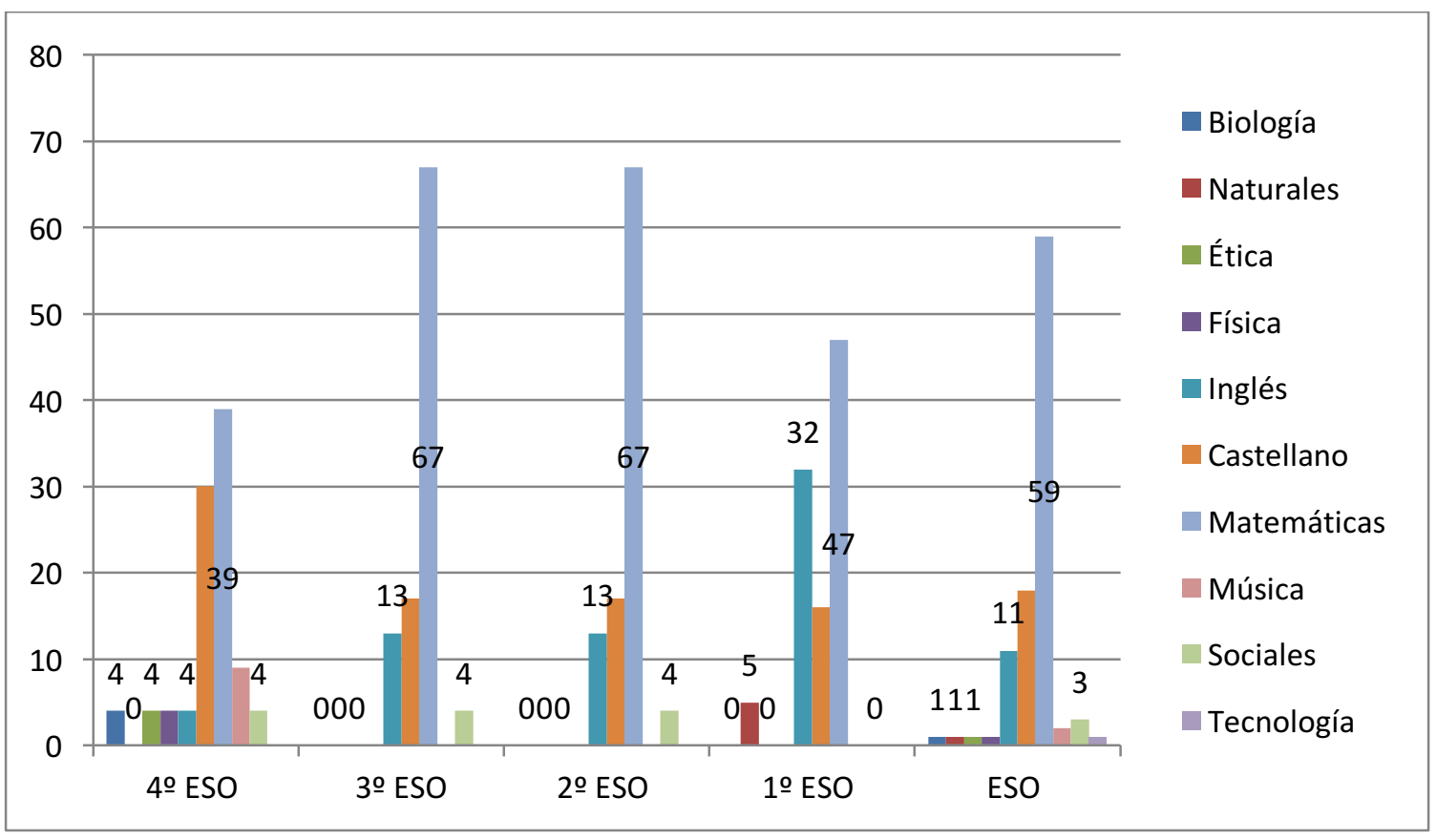

Menos importantes

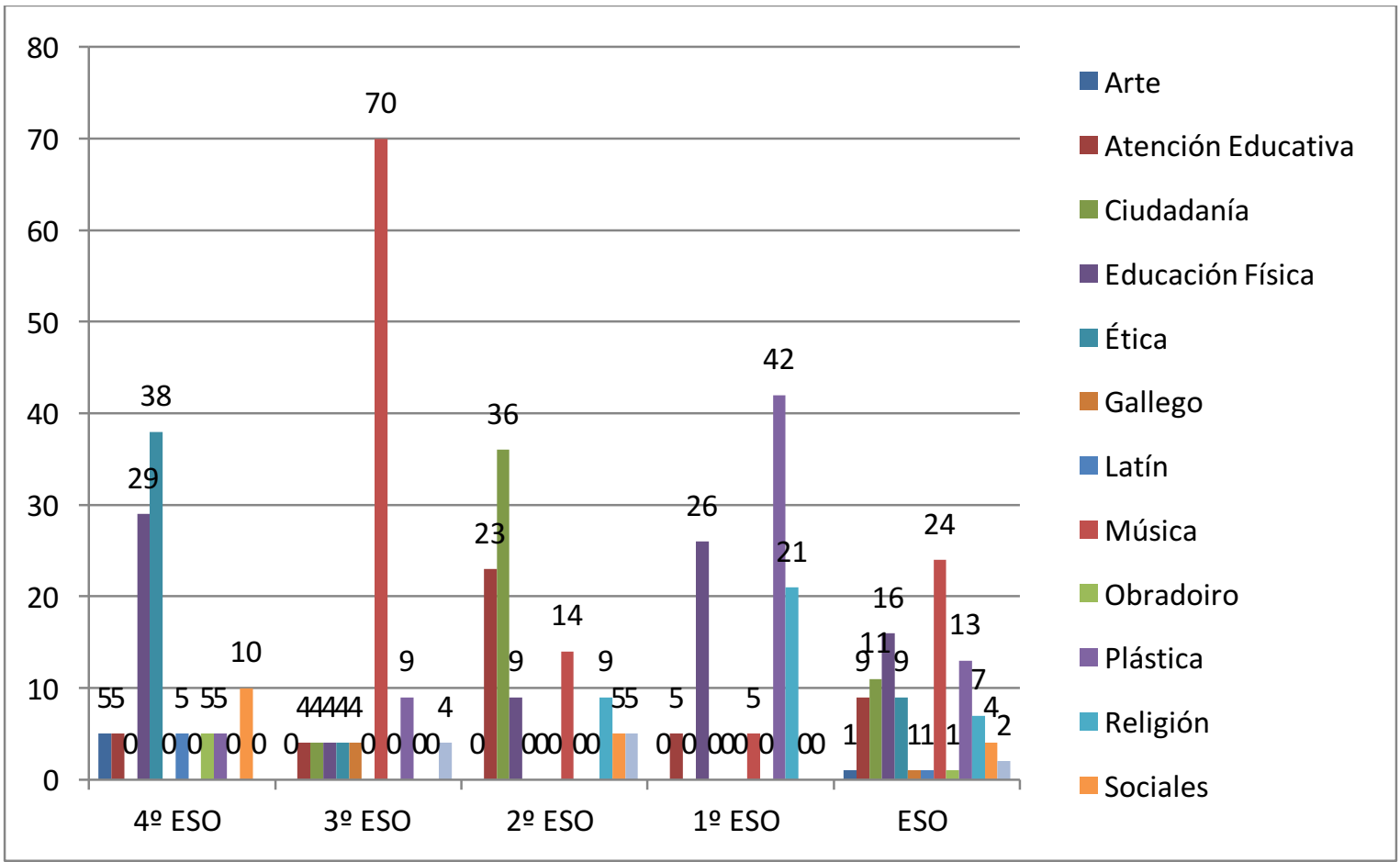

Fuente: elaboración propia. 
De igual manera, el alumnado reconoce que sus padres o tutores no valoran igual todas las materias en el $52 \%$ de los casos, aunque otro $44 \%$ asegura que en sus familias todas las materias gozan del mismo reconocimiento:

Gráfico 10. Valoración de los padres y tutores de las distintas disciplinas

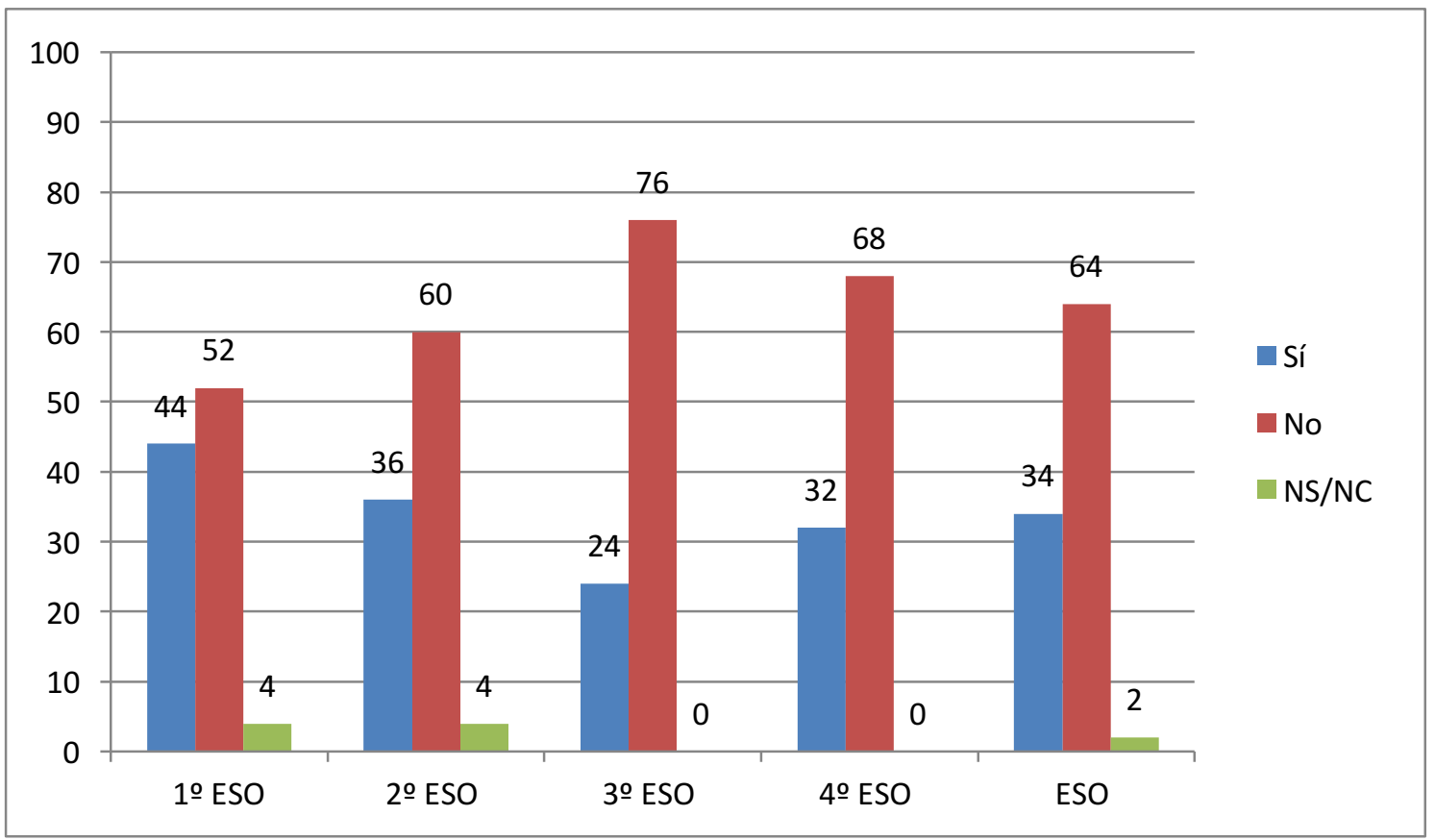

Fuente: elaboración propia.

Para los padres, nuevamente Matemáticas resulta ser la materia más importante y, además, en un porcentaje similar al concedido por sus hijos e hijas (56\%). Lengua Castellana y Literatura vuelve a situarse de nuevo en la segunda opción por orden de importancia con un $20 \%$.

Con respecto a la materia considerada por las familias como menos importante, un cuarto escoge Música (26\%), por lo que coincide la valoración del alumnado con la de sus familias tanto en mayor como en menor importancia. Los que coinciden con sus padres en considerar que todas las asignaturas tienen la misma importancia representan un $6 \%$ del total.

Gráfico 11. Comparativa entre las materias consideradas más y menos importantes por las familias

Más importantes

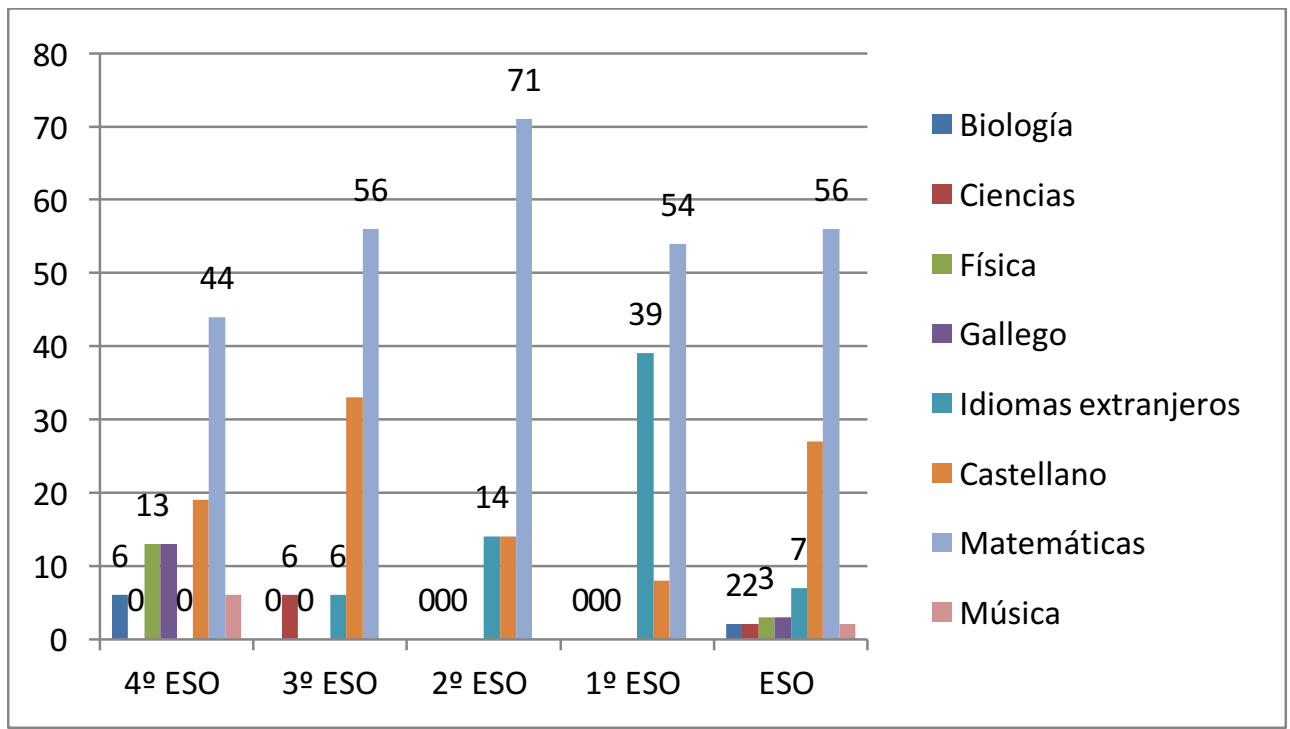




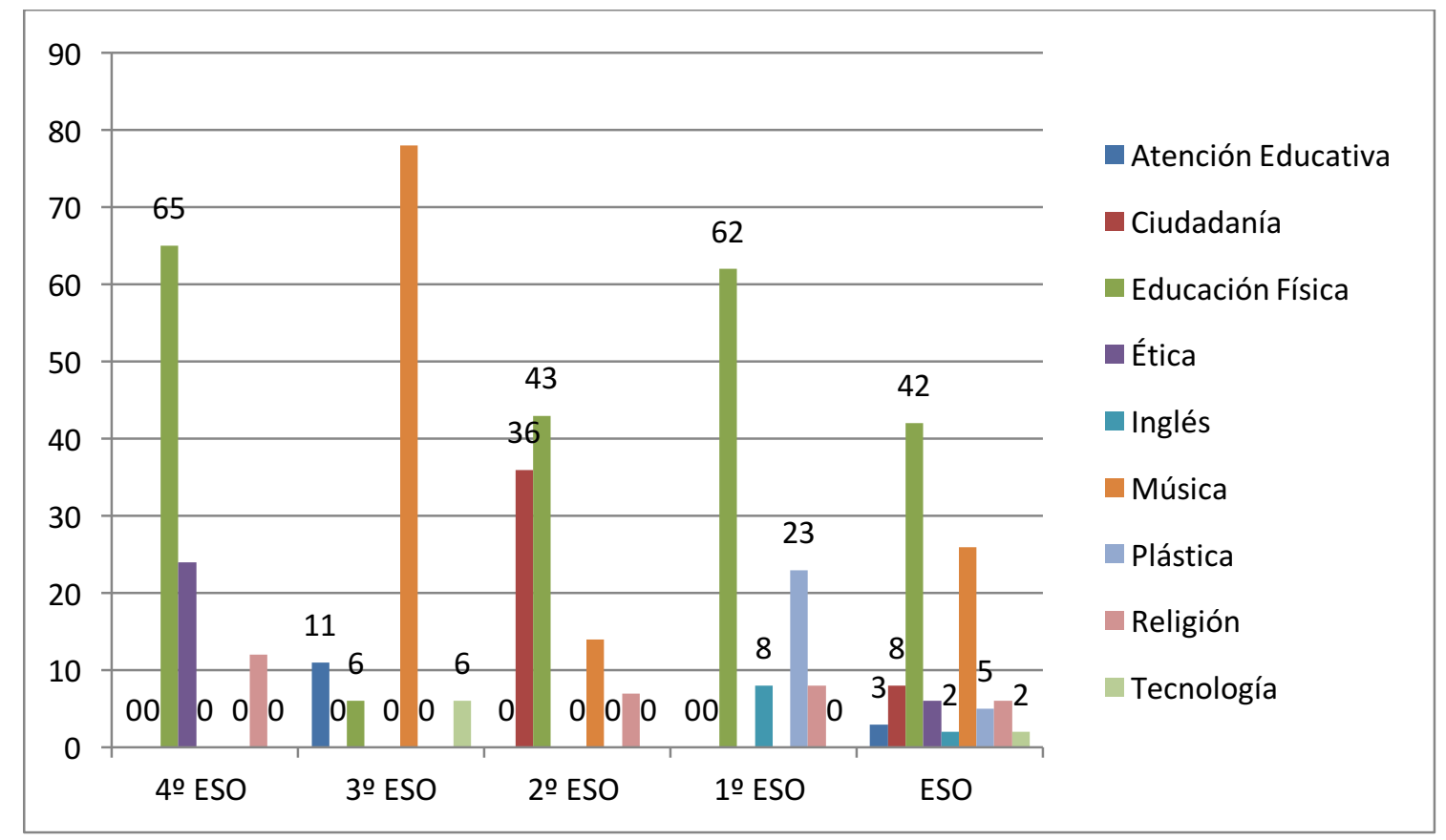

Fuente: elaboración propia.

Dos tercios de los encuestados considera que el centro potencia sus capacidades artísticas y la creatividad (66\%) y las tres cuartas partes (75\%) entienden en el instituto se potencian sus talentos personales, aunque de ellos, la mayoría (35\%) considera que solo en la mitad de las materias. Por otra parte, uno de cada cinco estudiantes (21\%) acusa que no aprecia que se desarrolle su talento en ninguna área de conocimiento.

Gráfico 12. Valoración de potenciación de las capacidades artísticas y la creatividad

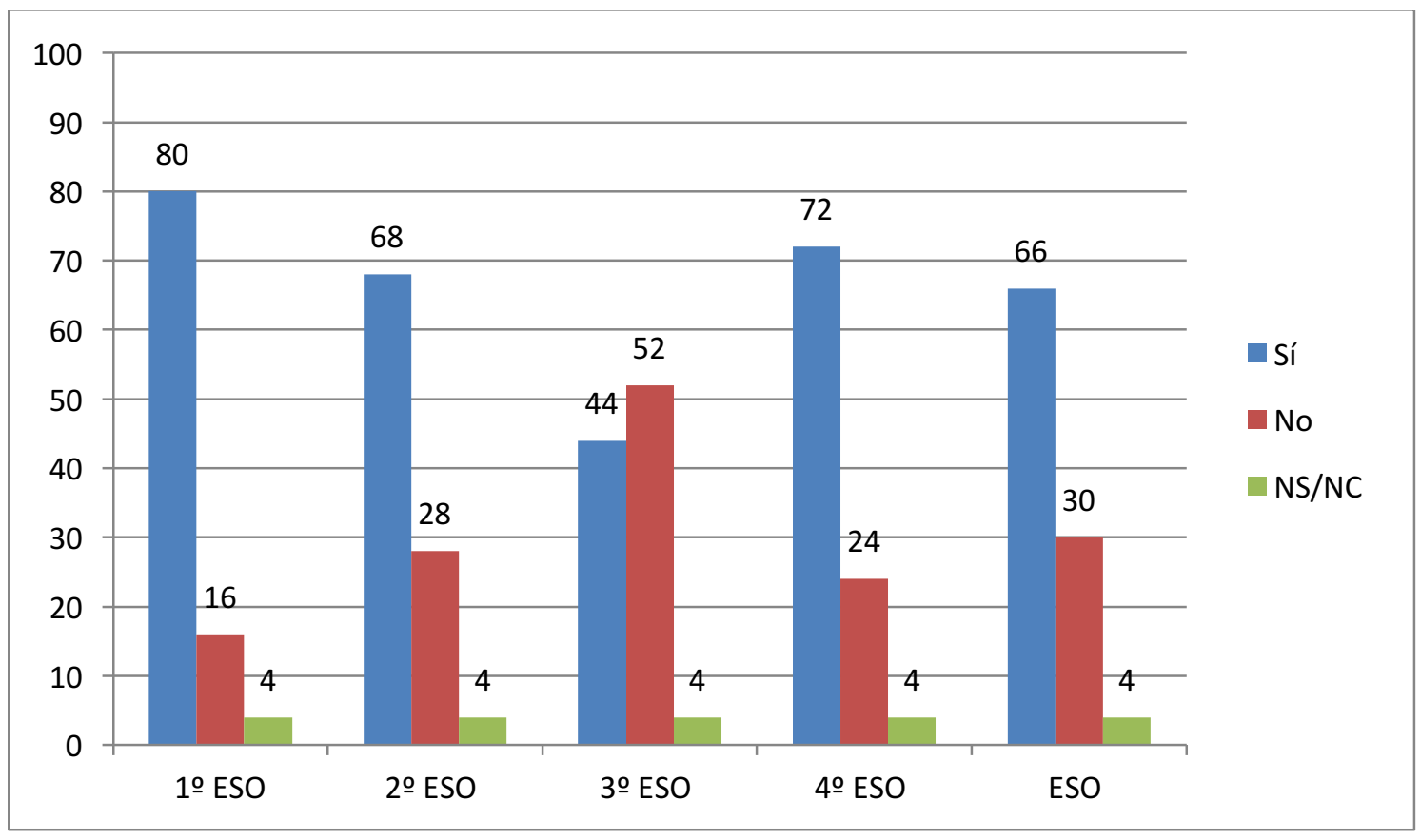

Fuente: elaboración propia. 
Gráfico 13. Valoración de potenciación de los talentos personales

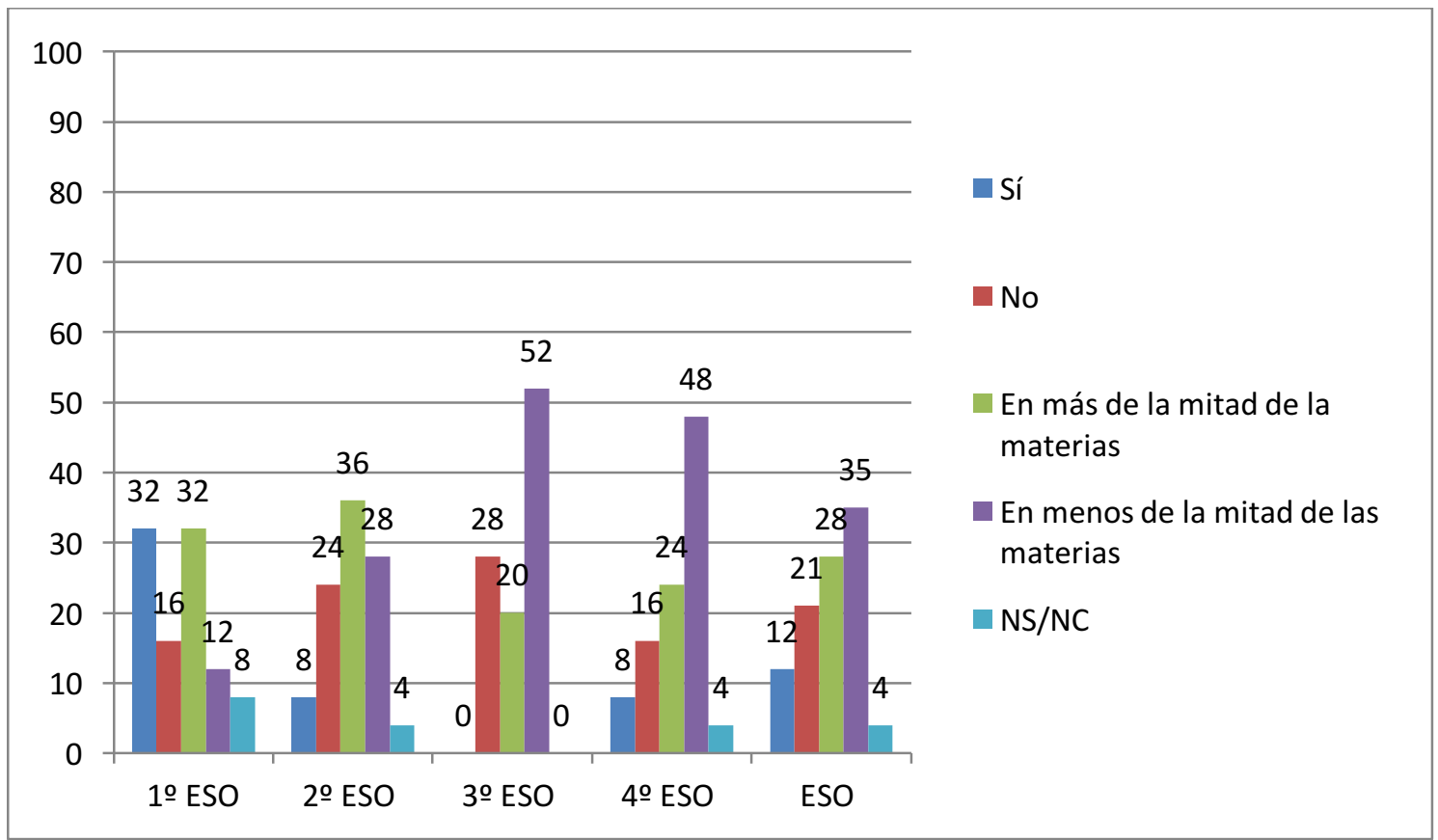

Fuente: elaboración propia.

Por otra parte, un $39 \%$ del alumnado considera que más de la mitad de sus profesores le motivan para aprender, a los que se suma un $21 \%$ que afirma que todo el profesorado potencia la motivación en su aprendizaje. Tan solo un $7 \%$ confiesa que sus profesores no le motivan para aprender.

Gráfico 14. Valoración del profesorado a la hora de fomentar la motivación por el aprendizaje

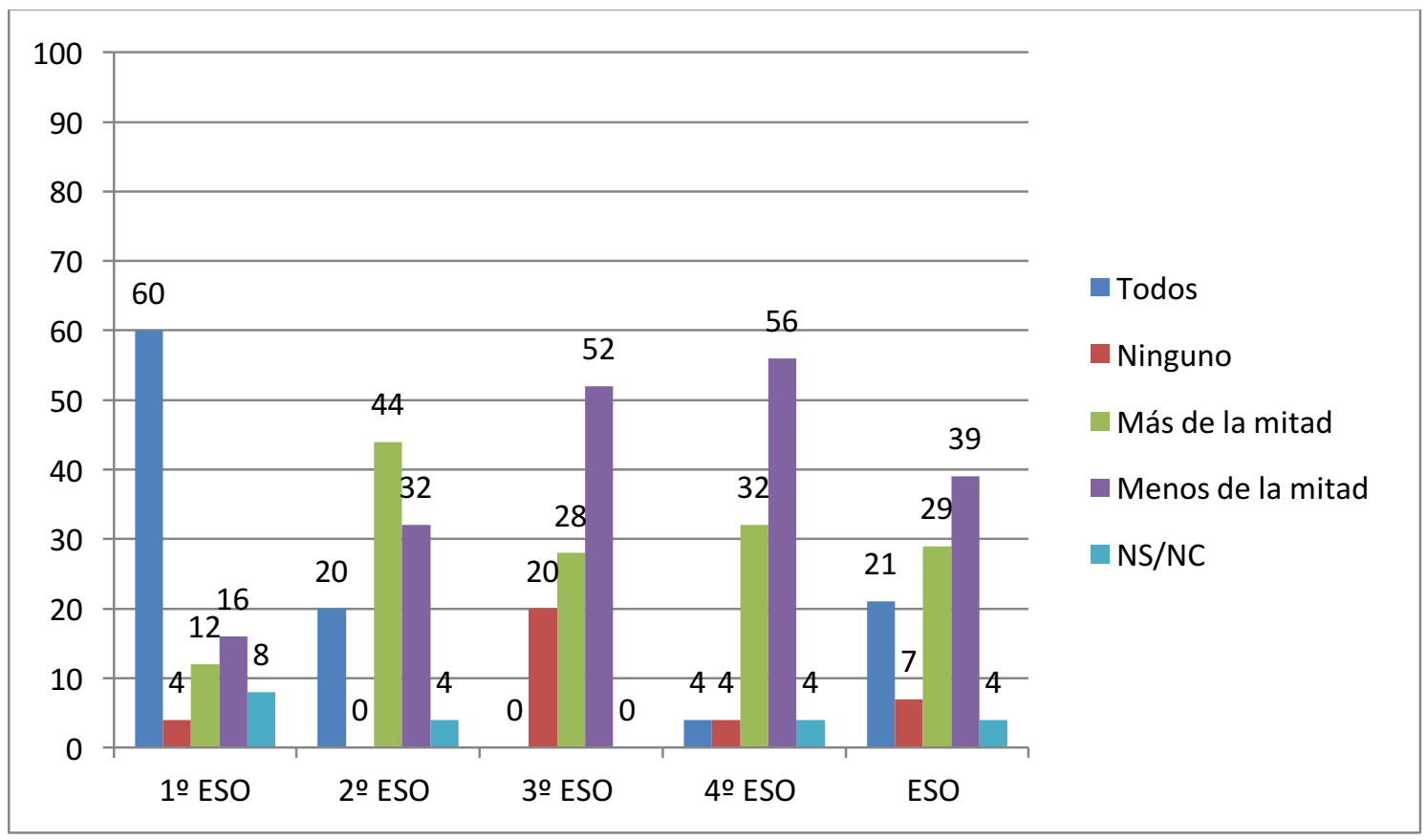

Fuente: elaboración propia.

De igual modo, de los que consideran que sus profesores se preocupan por su aprendizaje, el $89 \%$ señalan que también consideran que sus profesores los motivan para aprender: 
Gráfico 15. Alumnado motivado y que considera que el profesorado se preocupa por su aprendizaje

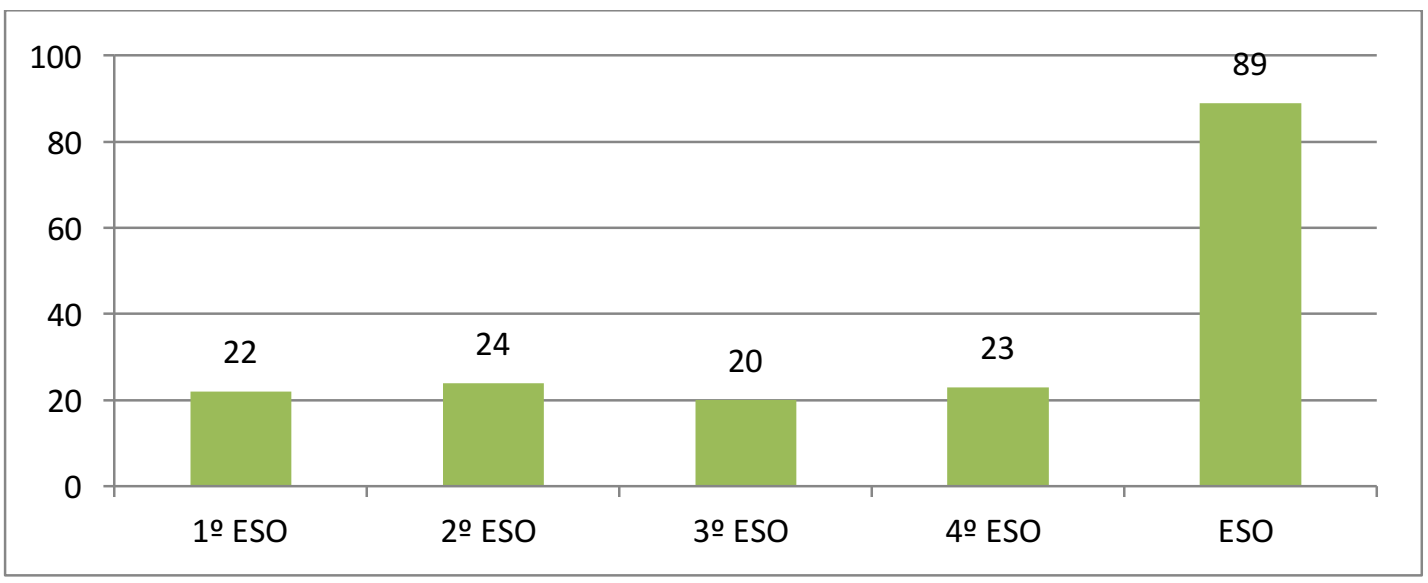

Fuente: elaboración propia.

Cuando se les pregunta a los estudiantes que no se sienten motivados qué aumentaría su motivación por el estudio, una amplia mayoría (69\%) apunta a un mayor dinamismo en las aulas. Un $8 \%$ apunta hacia temas de estudio más interesantes, otro $8 \%$ hacia la libre elección de las materias de estudio, otro $8 \%$ hacia la implantación de más horas de Educación Plástica y de Música y otro 8\% hacia a que los profesores no se enfaden en el aula:

Gráfico 16. Elementos que aumentarian la motivación en el aula

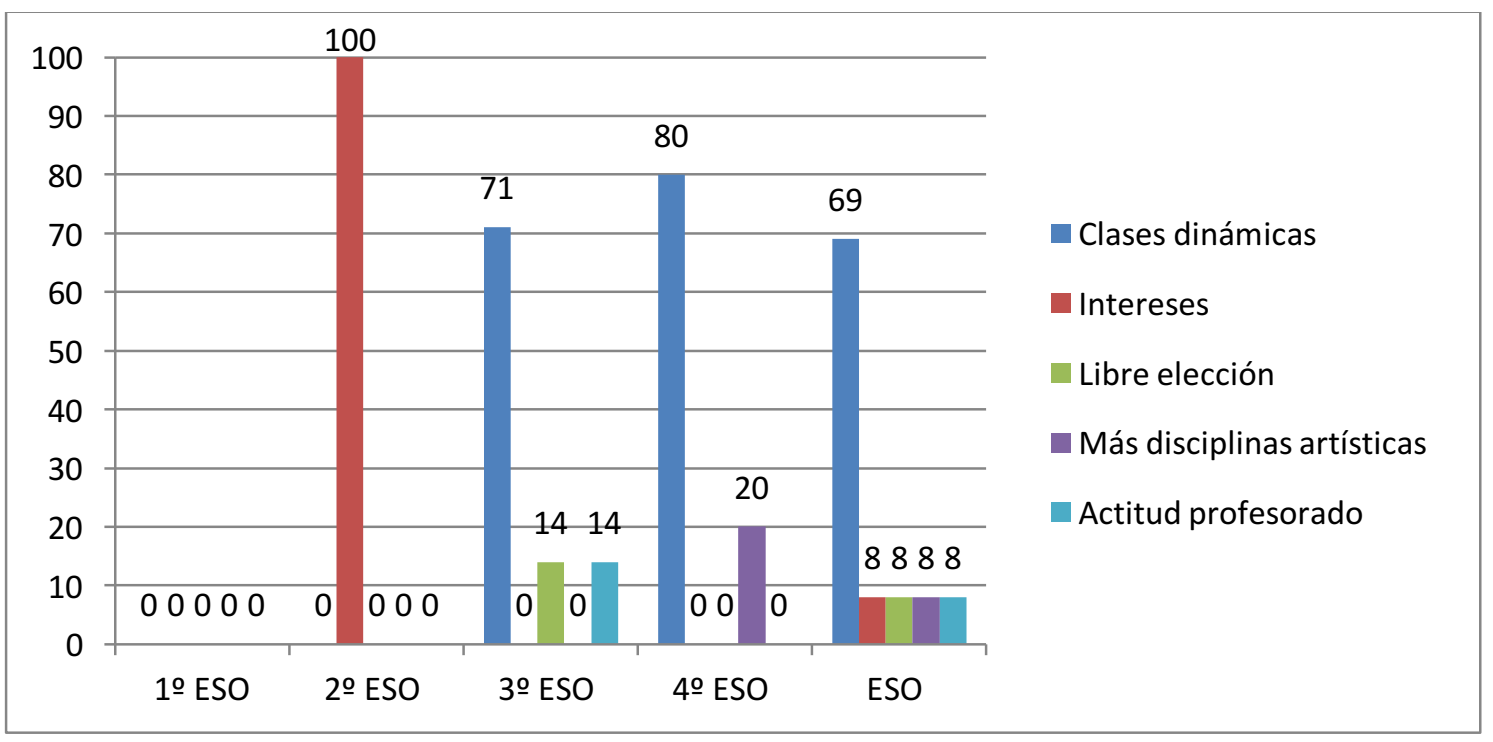

Fuente: elaboración propia.

Cinco de cada diez alumnos y alumnas (49\%) si pudieran modificar su plan de estudios pedirían una enseñanza más personalizada (recordemos que el $55 \%$ consideraba que no se ofrecía en el centro una enseñanza personalizada), mientras que otro $28 \%$ incluiría más materias que fomenten la creatividad y el desarrollo personal. Tan solo el 19\% de los estudiantes se muestra satisfecho con la situación actual y no modificaría nada. 
Gráfico 17. Intención de modificación del plan de estudios

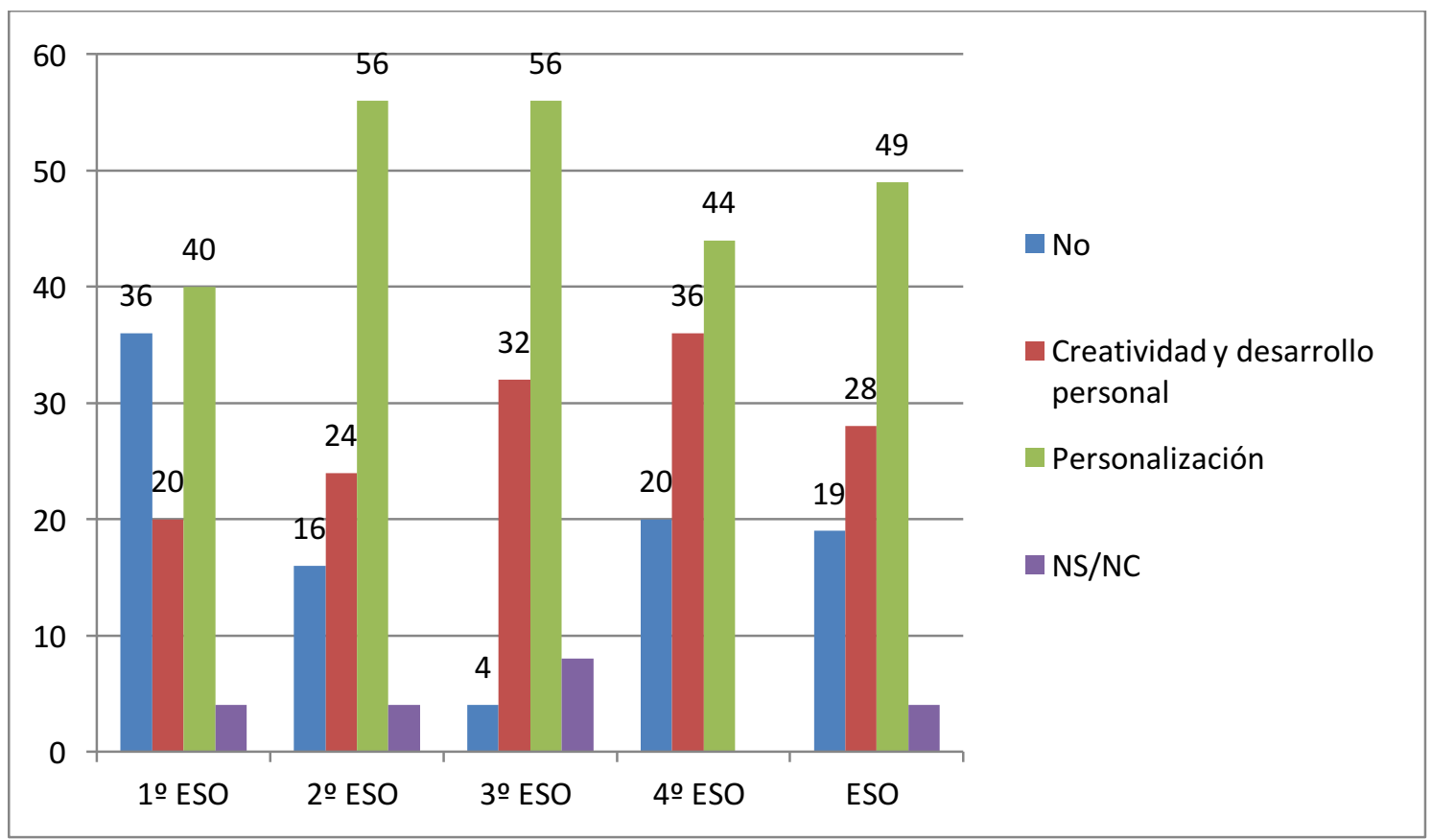

Fuente: elaboración propia.

Si cruzamos los resultados de aquellos alumnos y aquellas alumnas que se aburren en clase con los que desearían modificar su plan de estudios actual, encontramos que la mayoría, un $64 \%$, introduciría cambios:

Gráfico 18. Alumnado que se aburre en clase y modificaría su plan de estudios

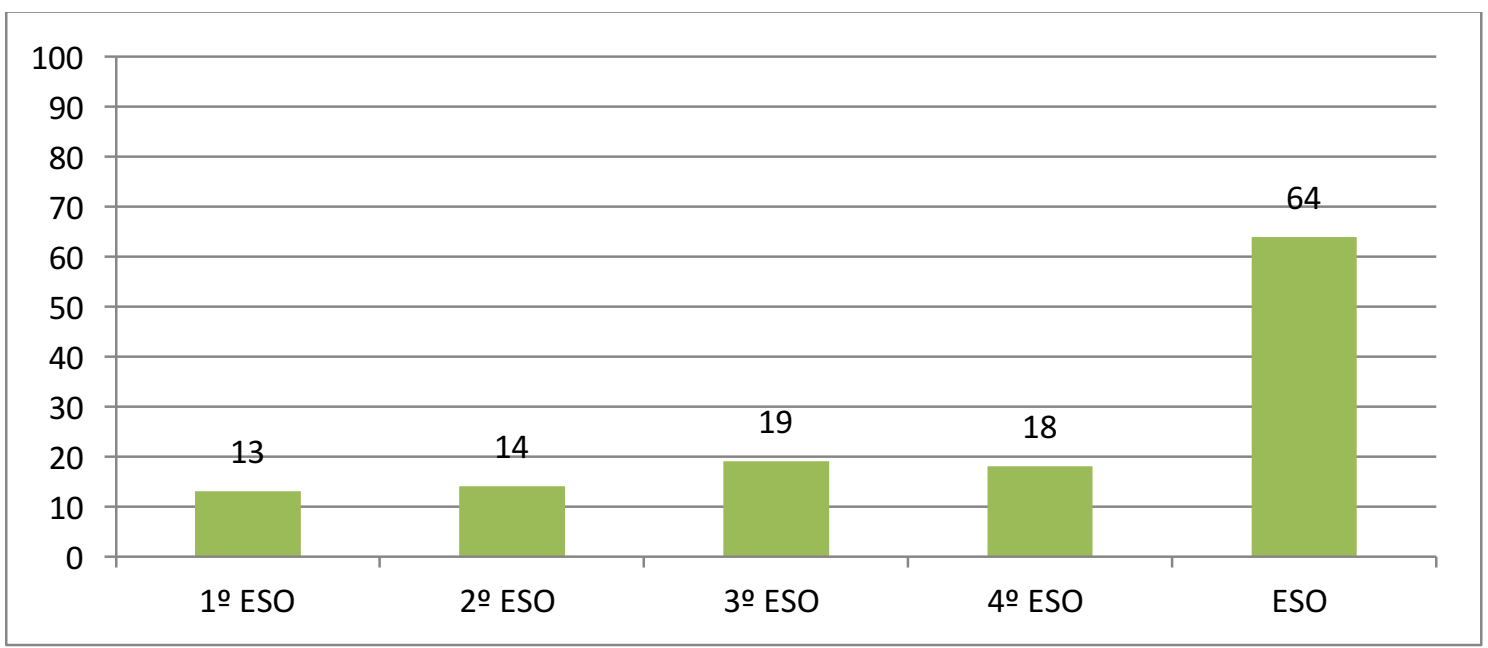

Fuente: elaboración propia.

\section{Discusión y conclusiones finales}

Seis de cada diez alumnos y alumnas de ESO (60\%) sienten que se les motiva lo suficiente durante su aprendizaje, aunque representan un $39 \%$ del total los que aprecian motivación en todas las materias. Con todo, a pesar de esta situación, siete de cada diez de los que no se sienten motivados $(69 \%)$ echan en falta clases más dinámicas y, si pudieran modificar su plan de estudios, a casi la mitad del conjunto del alumnado (49\%) le gustaría recibir una enseñanza más personalizada.

Ocho de cada diez estudiantes ( $80 \%$ ) consideran que ir a clase les supone una obligación -incluso, un $8 \%$ lo interpreta como una pérdida de tiempo, frente a un $8 \%$ que manifiesta satisfacción por el estudio. En efecto, solo un $19 \%$ de los estudiantes se encuentra satisfecho con su plan de estudios actual y no lo modificaría si tuviera opción de hacerlo. De igual modo, tres de cada cuatro estudiantes $(77 \%)$ revelan que se aburren en clase, por lo menos en algunas materias (76\%). El motivo principal que justifica ese aburrimiento en el aula lo encontramos en la labor docente individual, pues la materia que provoca los mayores índices de aburrimiento entre el alumnado varía en función del curso, de lo que se deduce que el desinterés lo 
provoca la manera de dar clase y no los propios contenidos curriculares. Aun así, casi todos los estudiantes (97\%) consideran que el profesorado se preocupa por su aprendizaje, aunque también es cierto que solo un $30 \%$ considera que lo hace todo el profesorado, mientras que un $29 \%$ entiende que tan solo se preocupa menos de la mitad de los docentes.

A pesar de que la mayoría de los estudiantes de secundaria (55\%) no aprecia indicios de una práctica docente personalizada, casi todos (85\%) consideran que se están potenciando sus capacidades individuales, aunque no en todas las materias (60\%). Igualmente, tres de cada cuatro estudiantes (75\%) consideran que se potencian sus talentos personales. De todas formas -y esto es una interpretación basada en la observación participante- puede ocurrir que el alumnado considere que se desarrollan sus talentos porque nunca han visto otra alternativa docente en el sistema educativo donde se han formado, lo que atribuiría las respuestas a una acomodación a los patrones estándar y a un desconocimiento de lo que implicaría el verdadero desarrollo del talento.

Un $66 \%$ de los consultados entiende que en el centro se potencian sus capacidades artísticas y la creatividad, aunque también es cierto que un $28 \%$ incluiría más materias que fomenten la creatividad y el desarrollado personal en su plan de estudios si pudiera modificarlo. Sin embargo, llama la atención que al alumnado (88\%) no le importan lo mismo todas las materias del currículo de secundaria: las disciplinas artísticas son las peor valoradas, frente a las Matemáticas que son consideradas como el área de conocimiento más importante tanto por los estudiantes (59\%) como por sus padres y madres $(56 \%)$.

En general, el alumnado de secundaria está contento con la docencia recibida y siente que el profesorado lo motiva y se preocupa por su aprendizaje, al tiempo que percibe que sus capacidades individuales y sus talentos se están desarrollando y potenciando de cara a la consecuente construcción de una marca personal propia. Le importan más las materias consideradas tradicionalmente de primera como Matemáticas y Lengua Castellana y Literatura y tanto ellos como sus familias restan importancia a las disciplinas artísticas.

\section{Bibliografía}

Aaker, D. A. (1991). Managing Brand Equity. Nueva York: Free Press.

Arqués, N. (2007). Y tú, ¿qué marca eres? Barcelona: Alienta Editorial.

Arruda, W. (2002). An Introduction to Personal Branding. A Revolution in the Way We Manage Our Careers. Reach Communications Consulting, 2002-2003.

Beltrán, M. (1979). Ciencia y Sociología. Madrid: CIS.

Chias, J. (2008). El márqueting. Barcelona: Editorial UOC.

Drucker, P. (2005). Gestionarse a uno mismo. Harvard-Deusto Business Review, 137.

Espinosa, R. (2012). Cómo definir misión, visión y valores, en la empresa [en línea]. Disponible en http://robertoespinosa.es/2012/10/14/como-definirmision-vision-y-valores-en-la-empresa/ [Consulta: 2014, 8 de septiembre].

Hernández, R.; Fernández, C.; Baptista, P. (2007). Fundamentos de metodología de la investigación (adaptación de la primera edición mexicana). Madrid: McGraw Hill.

Kaputa, C. (2005). The Self Brand Mindset. SelfBrand [en línea]. [Consulta: 2015, 22 de septiembre].

Kotler, P.; Armstrong, G.; Saunders, J.; Wong, V.; Miquel, S.; Bigné, J. E. e Cámara, D. (2002). Introducción al marketing (2ª ed. europea). Madrid: Pearson.

Martín, M. C. (2012). ¿Porque es importante tener una marca personal propia? [en línea]. Disponible en http://www.maricarmenmartin.com/porquees-importante-tener-una-marca-personal-propia/ [Consulta: 2014, 20 de diciembre].

Pérez Ortega, A. (2008). Marca Personal. Madrid: ESIC.

Pérez Ortega, A. (2013). Te van a oír. Construye tu plataforma personal para darte a conocer. Barcelona: Alienta Editorial.

Peters, T. (1997). The Brand Called You. Fast Company, 10, 83-86.

Sixto, J. (2013). Las redes sociales como estrategia de marketing online. Lisboa: Editora Media XXI.

Soyunamarca (2014). 7 claves de un plan de marketing personal 2.0 [en línea]. Disponible en http://www.soyunamarca.com/2014/01/7-claves-deun-plan-de-marketing-personal-2-0/ [Consulta 2014, 5 de septiembre].

Spencer, L.M. y Spencer, S.M. (1993). Competence at Work. Nueva York: John Wiley and Sons. 
Cómo citar este artículo en bibliografías - How to cite this article in bibliographies / references:

SIXTO-GARCÍA, J.; (2017): "Estudio sobre la identificación de talentos, competencias y habilidades para el desarrollo de la marca personal". En Revista de la Asociación Española de Investigación de la Comunicación, vol. 4, número 7, pp. 102-118. 